\title{
How Not to Be Misled by Disorders Mimicking Angioedema: A Review of Pseudoangioedema
}

\author{
Michelle Fog Andersen ${ }^{a}$ Hilary J. Longhurst ${ }^{d}$ Eva Rye Rasmussen ${ }^{b}$ \\ Anette Bygum ${ }^{c}$ \\ a Department of Otorhinolaryngology, Head and Neck Surgery, University Hospital of Sjaelland, Koege, \\ ${ }^{b}$ Department of Otorhinolaryngology, Head and Neck Surgery, University Hospital of Copenhagen, Copenhagen, \\ and 'HAE Centre Denmark, Department of Dermatology and Allergy Centre, Odense University Hospital, \\ Odense, Denmark; ${ }^{\text {d}}$ Department of Immunology, Barts Health NHS Trust, London, UK
}

\section{Key Words}

Angioedema $\cdot$ Pseudoangioedema Differential diagnoses

\section{Abstract}

Background: Angioedema is a vascular reaction involving the lower dermis, subcutis and/or submucosal tissue and causing a temporary localized swelling in any part of the body. For many health care professionals, the diagnosis presents an ongoing challenge; several disorders may manifest with subcutaneous or submucosal swelling and falsely be assumed to be angioedema. The clinicians at the emergency department and in the immunology/allergy clinics must be skilled at recognizing the features of angioedema and its differential diagnosis. Methods: The review is based on a literature search with specific indexing terms in PubMed, a review of bibliographies and the authors' clinical experience. Results: The most essential diseases that mimic angioedema, the so-called pseudoangioedemas, will each be discussed and illustrated by clinical photos, pointing out key features that help clarify the diagnoses and differentiate these from classic angioedema. Conclusions: A variety of dermatologic conditions can cause swelling that resembles angioedema, some with a potentially fatal outcome if misdiagnosed. Knowledge of pseudoangioedema is fundamental in the emergency setting when handling patients with edema and should be kept in mind when assessing an atypical angioedema case.

(c) 2016 S. Karger AG, Basel

\section{Introduction}

Angioedema, with the synonyms angioneurotic edema or Quincke's edema, was originally described in 1882 by the German internist and surgeon Heinrich Quincke [1]. The condition is characterized by swelling just below the surface of the skin and/or mucosa, caused by a sudden increase in endothelial permeability with extravasation of intravascular fluid into the interstitial tissues. A variety of mechanisms can trigger the process, causing angioedema to be classified into two main categories: hereditary and acquired angioedema [2-4]. Hereditary angioedema (HAE) is a rare form of severe angioedema caused by ge-

\section{KARGER}

E-Mail karger@karger.com

www.karger.com/iaa
C 2016 S. Karger AG, Basel

$1018-2438 / 16 / 1693-0163 \$ 39.50 / 0$
Correspondence to: Dr. Michelle Fog Andersen

Department of Otorhinolaryngology, Head and Neck Surgery

University Hospital of Sjaelland

Lykkebaekvej 1, DK-4600 Koege (Denmark)

E-Mail michellefog@yahoo.com 
netic mutations in the complement $\mathrm{C} 1$ inhibitor $(\mathrm{C} 1$ INH) gene, Serping1, leading to a decrease in C1-INH. This leads to recurrent episodes of uncontrolled spontaneous activation of the contact system resulting in the release of a potent vasoactive peptide named bradykinin. HAE with normal C1-INH was primarily discovered in women [5-7], and has been described with factor XII mutations (FXII-HAE) $[6,8]$ and of unknown origin. Acquired angioedema can be related to C1-INH deficiency as well, but is most commonly mediated by an excess of local histamine and other vasoactive mediators released by mast cells and basophils. The cause is often idiopathic but can be immunologic, such as allergic reactions initiated by immunoglobulin E-mediated hypersensitivity to foods or drugs. Acquired angioedema can also occur as a nonimmunologic side effect to certain drugs, the most common being cardiovascular drugs, containing angiotensin-converting enzyme inhibitors, which interferes with bradykinin degradation. Cytokine-mediated angioedema is a relatively common complica163tion of treatment with biological treatments, particularly monoclonal antibodies.

When working in the clinical setting, it is essential to remember that not all swellings are angioedema. A number of medical conditions can cause swelling that resemble angioedema and are often erroneously labeled as such, due to low awareness of their typical hallmarks amongst medical staff in both the emergency and outpatient setting $[9,10]$. Misdiagnosis may lead to ineffective management of these potentially serious conditions, as most do not respond to conventional angioedema treatment, making a correct determination of the root causes of symptoms essential and, in some cases, even life-saving. An understanding of clinical features unique to angioedema as well as its differential diagnosis, is therefore of great importance and will help the physician to target the correct underlying pathophysiology. Syndromes that masquerade as angioedema are referred to as pseudoangioedemas in the literature and should be considered in any patient presenting with atypical manifestations [10]. In this review, we focus on the most common and serious differential diagnoses of angioedema supported by illustrative clinical photos.

\section{Material and Methods}

Studies on angioedema and its differential diagnoses were found by conducting a systematic literature search in PubMed (Medline), using the key words 'angioedema', 'differential diagnosis', 'pseudoangioedema', 'angioedema mimickers', 'acute contact dermatitis', 'drug rash with eosinophilia and systemic symptoms', 'dermatomyositis', 'morbus morbihan', 'superior vena cava syn- drome', 'hypothyroidism', 'subcutaneous emphysema', 'orofacial granulomatosis', 'hypocomplementemic urticarial vasculitis', 'clarkson's disease', 'gleich's syndrome', 'cluster headache', 'idiopathic edema' and combinations of these search words. Only articles in English published since the year 2005 were included in the initial search. The total search produced 14,331 hits, thus proving the need for a more relevant search strategy. The search was limited to full-text articles, which were systematic reviews, meta-analyses, multicenter studies, clinical trials, randomized clinical trials or case reports. Using this approach, 1,342 articles were found. In order to find the original articles and identify additional pertinent reports, selected reviews were then screened for relevant crossreferences and examined, with the result of 4 new original publications. A total of 42 articles were yielded from these search results. The search was terminated on the 1st of September 2015.

\section{Results}

\section{What Is Angioedema?}

Angioedema is a clinical symptom defined by local swelling of the deeper layers of the skin, mucous membranes, or both, including the gastrointestinal tract and upper airway. Although the swelling can affect any part of the body, it has a predilection for areas with loose connective tissue, including the face (especially the lips, tongue and periorbital area), pharynx, larynx, abdomen, genitalia and extremities [11-13]. The swellings manifest as recurrent episodes of pronounced localized edema with ill-defined margins. Unlike other forms of edema, angioedema is nonpitting, often asymmetric and has a tendency not to involve gravitationally dependent areas. The skin is usually normal in color, but can be slightly erythematous. The majority of patients with angioedema describe a tingling, slightly numb or even burning sensation of the affected site, while itching is not a typical symptom. The swelling is typically of slow onset over several hours and lasts for $<72 \mathrm{~h}$, resolving spontaneously without staining or desquamation of the skin. However, angioedema can have a very rapid onset when it occurs due to anaphylaxis. Over half of patients have concomitant urticaria $[11,12]$.

\section{Pseudoangioedema}

There are several conditions presenting with subcutaneous swelling that superficially resemble angioedema. Based on key signs and symptoms (online suppl. table 1; see www.karger.com/doi/10.1159/000445835), these socalled pseudoangioedemas can clinically be distinguished from true angioedema. The most common and important diseases that can mimic angioedema are listed below. 
Fig. 1. Acute contact dermatitis with severe facial swelling after hair dyeing.

Fig. 2. Generalized edematous swelling and morbilliform rash in a patient with DRESS.
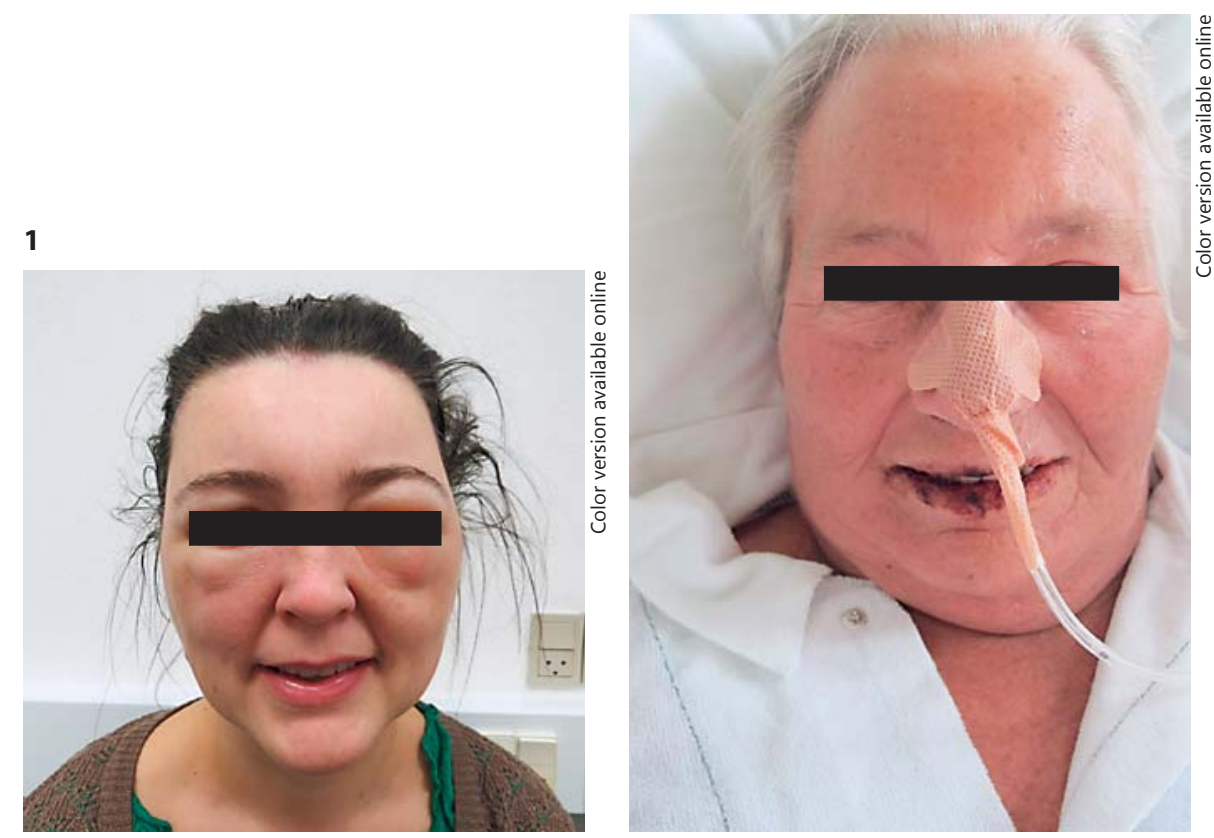

\section{Acute Contact Dermatitis}

Acute contact dermatitis is an inflammatory response of the skin induced by contact with a foreign substance. The reaction can be triggered by direct interaction with an irritating agent (irritant contact dermatitis) or allergenic chemical substance (allergic contact dermatitis) causing a type IV allergic reaction [14]. Acute contact dermatitis of the face is often misdiagnosed as angioedema, as it can cause severe swelling of the facial and periorbital skin, especially after contact with hair dye (fig. 1) [14, 15]. The reaction can become so severe that intubation may be necessary. It can be distinguished from angioedema and other pseudoangioedemas by demonstration of superficial erythema, dermatitis, prominent pain or pruritus and a history of exposure to a foreign substance. Finally, the skin will often peel as the swelling resolves, in contrast to patients with angioedema [14]. Antihistamines are ineffective, but symptoms respond to corticosteroids given topically or systemically. Diagnosis is verified by patch testing and the management involves strict avoidance of any contact allergens identified, along with withdrawal of the corticosteroids once symptoms are well controlled.

\section{Drug Rash with Eosinophilia and Systemic Symptoms}

Drug rash with eosinophilia and systemic symptoms (DRESS) refers to an uncommon but rather severe adverse drug-induced skin reaction. Among a wide list of drugs associated with this reaction, aromatic anticonvulsants (phenytoin, phenobarbital and carbamazepine) are the most common [16]. DRESS may mimic angioedema due to its clinical manifestation with facial or more widespread edema, which is accompanied by a diffuse, morbilliform rash (fig. 2) [17]. Other characteristic findings include fever, eosinophilia, lymphadenopathy and internal organ involvement, mainly the liver and kidneys, which differentiate this condition from angioedema. The onset of the disease is usually seen within 6 weeks after the initiation of drug exposure and DRESS has a longer duration than most allergic drug reactions $[16,18]$. In fact, the symptoms can even exacerbate despite discontinuation of the drug. A history of the patient's medication, together with objective findings and blood tests, is therefore of utmost importance. Traditional patch testing cannot be used to confirm the diagnosis, which has to be clinical. Management consists of discontinuation of the causative drug. Most patients recover completely after drug withdrawal, but treatment regimens with corticosteroids are commonly used as well [18].

\section{Dermatomyositis}

Dermatomyositis is a common idiopathic inflammatory myopathy that affects both skeletal muscle and the skin [19]. Although the etiology is poorly understood, an immunological pathogenesis has been suggested. The disease is characterized by proximal muscle weakness and cutaneous eruption in the form of erythema. The most common cutaneous features include the heliotrope rash: a distinctive reddish-purple erythematous rash around 
3

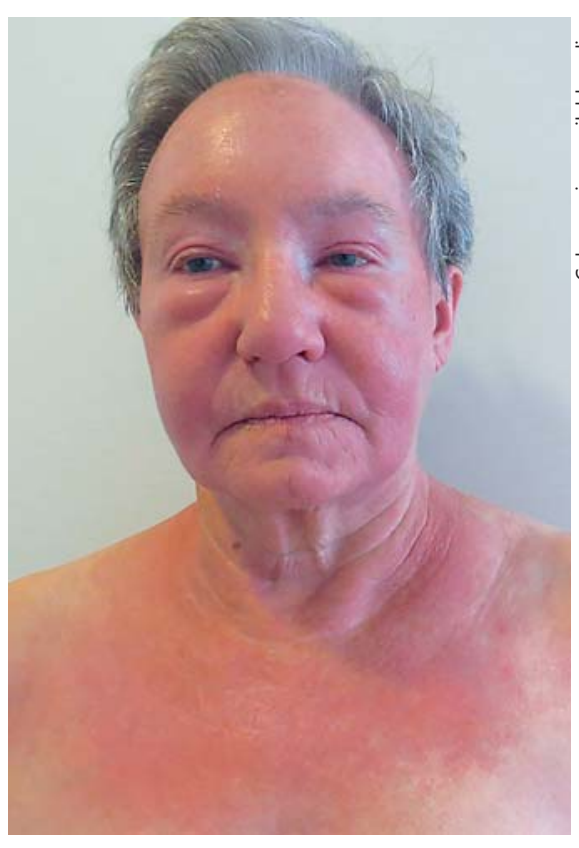

4

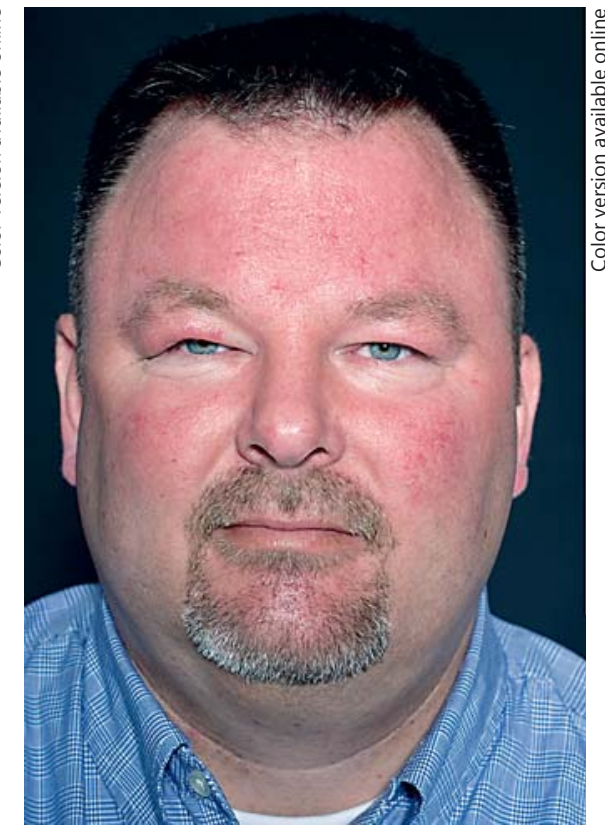

Fig. 3. Heliotrope rash and edema and rash in the shawl area in a patient with dermatomyositis.

Fig. 4. Persistent swelling of the forehead, cheeks and upper eyelids in a patient with Morbus Morbihan.
However, reported therapy includes long-term systemic corticosteroids and/or oral antibiotics such as doxycycline and isotretinoin [24].

\section{Superior Vena Cava Syndrome}

Superior vena cava syndrome is a group of symptoms caused by obstruction and thereby impaired blood flow through the superior vena cava into the right atrium. In most cases, the obstruction is caused by a malignant tumor within the thorax. The clinical manifestations of superior vena cava syndrome usually develop slowly and include dyspnea, cough and hoarseness. Because the drainage of blood to the heart is obstructed, the syndrome can, in the early stages, masquerade as angioedema, due to a gradual development of edema in the face and upper extremities (fig. 5) [25, 26]. Clues to differentiate the 2 diagnoses include vein distension across the chest and neck as well as an increase of signs when the patient is in a supine position $[11,27]$. X-ray or CT scan of the chest including the thoracic inlet usually confirms the diagnosis and further management is then undertaken by the thoracic oncology team.

\section{Hypothyroidism}

Insufficient production of thyroid hormones by the thyroid gland causes hypothyroidism, which is most often autoimmune [28]. The condition presents with a wide array of symptoms including weight gain, constipation, dry skin, thinning of hair, hoarse voice, fatigue, lethargy, 
5

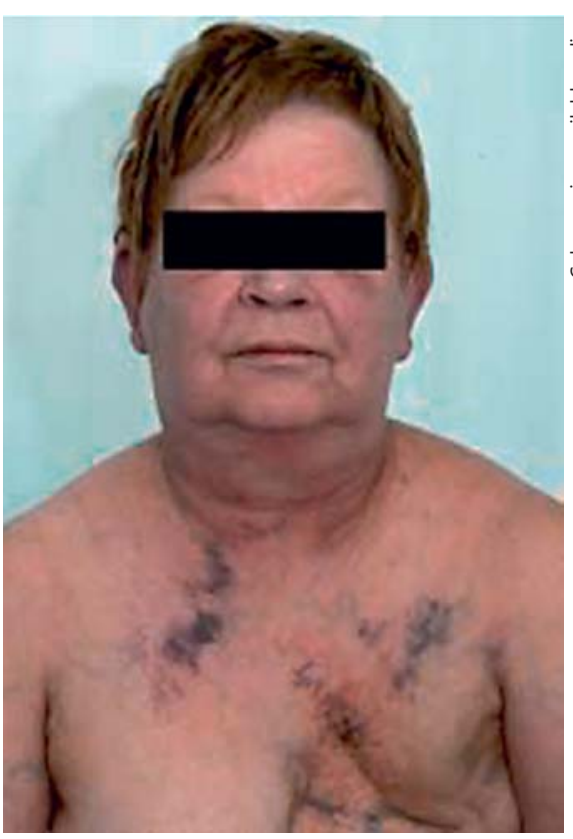

6

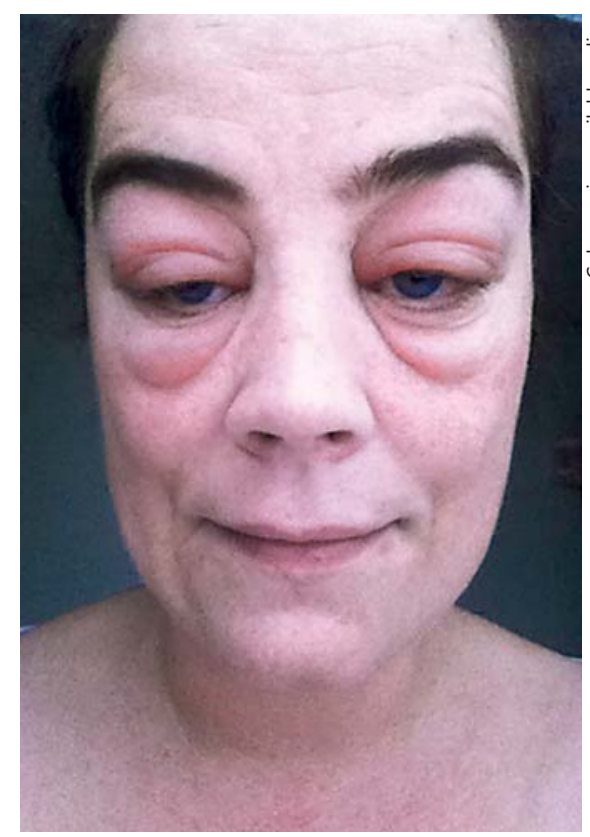

7

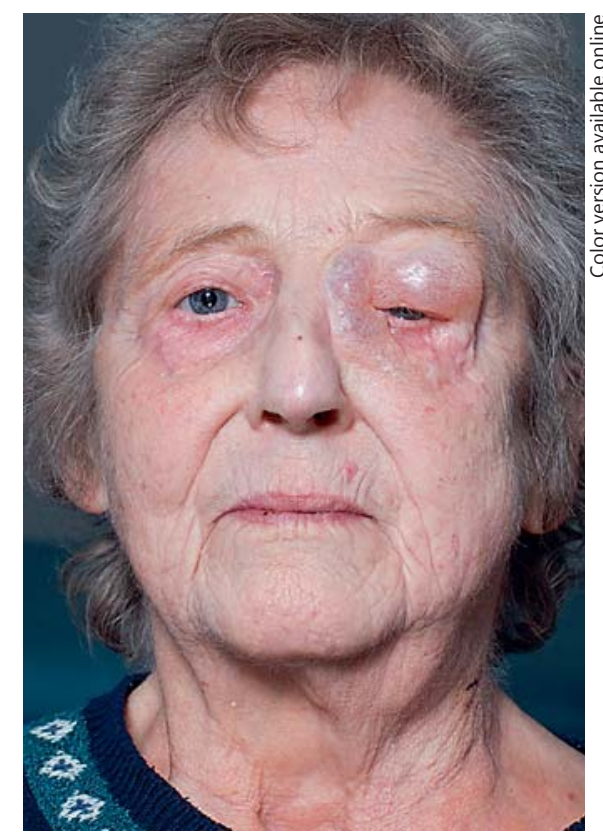

Fig. 5. Facial and neck swelling accompanied by dilatation of veins and cyanosis in a patient with superior vena cava syndrome. Photo credit: Tarec Christoffer El-Galaly, MD, and Nina Keldsen, MD, reprinted with permission [Ugeskr Læger 2007;169:3118].

Fig. 6. Severe manifestation of periorbital edema in a patient with hypothyroidism.

Fig. 7. Subcutaneous emphysema with severe swelling of the left chin, eyelids and neck after a simple dental procedure.

depression and cold intolerance. Severe hypothyroidism can manifest with puffiness of the face and lips very similar to angioedema (fig. 6). When generalized nonpitting edema (myxedema) becomes a manifestation, periorbital edema is often seen as a symptom. Nonetheless, it is not transient like angioedema $[10,17]$. Identification of the diagnosis is based on clinical features and low levels of thyroid hormones. The treatment of choice for hypothyroidism is thyroxine replacement [28].

\section{Subcutaneous Emphysema}

Air bubbles or other gases trapped in the subcutaneous tissues, namely subcutaneous emphysema, cause a sudden onset of swelling in the affected area [29]. Air can migrate through the various fascial planes to involve the thorax, abdominal wall, perineal region, extremities and most often the neck or face (fig. 7), causing the condition to mimic angioedema. The air may become trapped as a result of surgery or trauma, or can occasionally develop spontaneously. Subcutaneous emphysema can usually be diagnosed clinically by crepitus, a characteristic crackling sensation created as the gas is pushed through the tissue during palpation $[29,30]$. In patients with this significant finding, the differential diagnosis of angioedema is ruled out. In doubtful cases, an X-ray or CT scan could be performed to illustrate the air beneath the skin surface and to identify the source of the emphysema.

\section{Orofacial Granulomatosis}

Orofacial granulomatosis represents a group of chronic diseases affecting the soft tissues of the oral and maxillofacial region secondary to an underlying granulomatous inflammation [31]. The clinical presentation commonly shows persistent swelling of the lips (fig. 8). The group includes Melkersson-Rosenthal syndrome, an idiopathic disorder represented by a classic triad of persisting lip or facial swelling, facial nerve paralysis and fissured dorsal tongue (lingua plicata). Monosymptomatic cases with labial involvement alone are referred to as cheilitis granulomatosa. The orofacial edema is painless and asymmetrical, most often affecting the upper lip. Clinically, it is similar to angioedema and plays an essential role as a differential diagnosis [10, 31, 32]. However, its chronic nature should distinguish it from typical angioedema. The etiology remains unclear but has been linked to an abnormal immune reaction. Diagnosis is confirmed by histology. Management often requires the use of corticosteroids or immunosuppression [32]. 
Fig. 8. Persistent swelling of the lower lip in a patient with orofacial granulomatosis.

Fig. 9. Edematous urticarial plaques in a patient with hypocomplementemic urticarial vasculitis syndrome.

Fig. 10. Generalized edematous swelling in a patient with Clarkson's disease. Photo credit: Knud Bonnet Yderstræede, MD.

Fig. 11. Characteristic left periorbital edema and partial ptosis, with left conjunctival injection and tear formation during a cluster headache attack. Photo credit: Horton Hovedpineforening (Danish Association for Patients with Cluster Headache), www. hortonforeningen.dk.
8

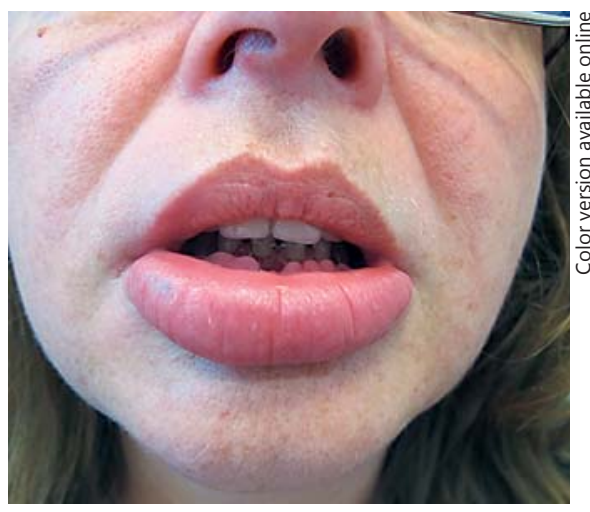

9

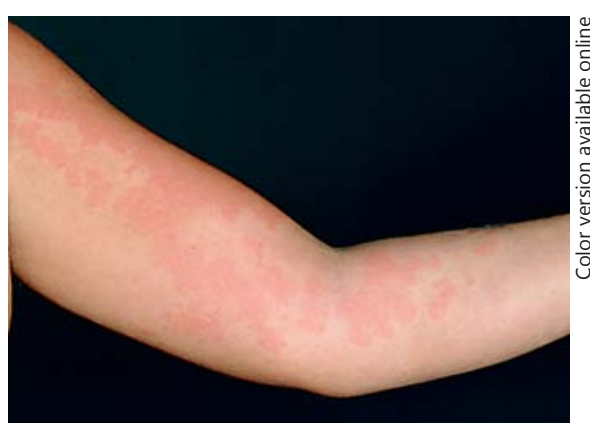

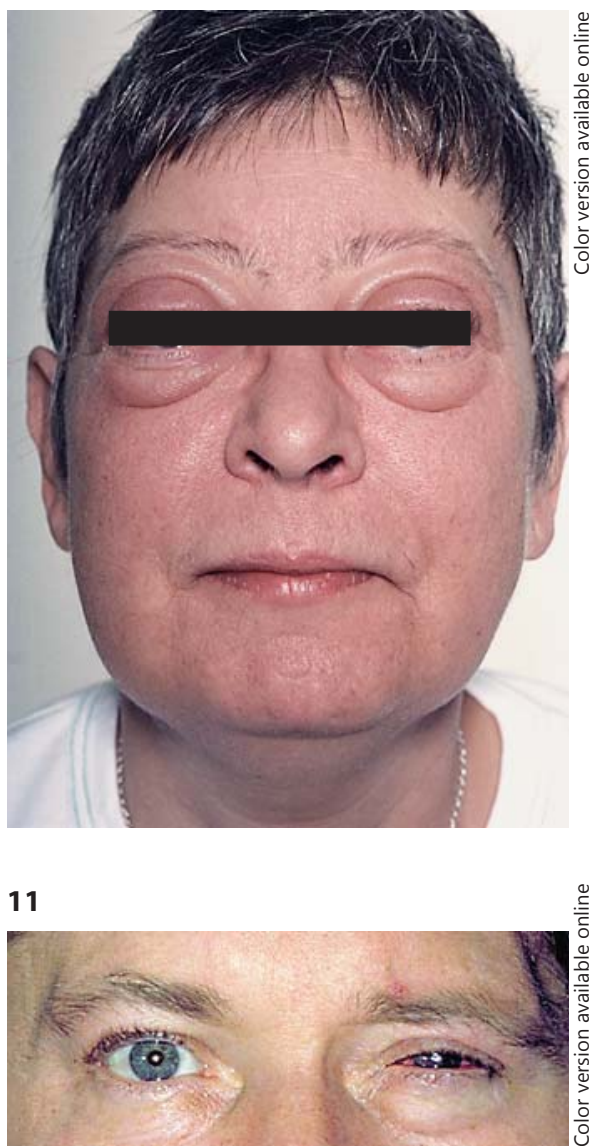

Hypocomplementemic Urticarial Vasculitis Syndrome

Hypocomplementemic urticarial vasculitis syndrome is a form of severe, cutaneous, small-vessel vasculitis characterized by urticaria and abnormally low levels of complements $\mathrm{C} 1 \mathrm{q}, \mathrm{C} 3$ and $\mathrm{C} 4$ with $\mathrm{C} 1 \mathrm{q}$ antibodies [33, 34]. The most distinctive manifestation of this rare disease is recurrent episodes of chronic, nonpruritic, urticarial skin lesions (fig. 9) associated with systemic involvement including pulmonary disease, abdominal pain, leukocytoclastic vasculitis, arthritis, arthralgia and glomerulonephritis. Underlying malignancy, infection or connective-tissue disease should be excluded. In addition, angioedema is the initial clinical presentation in over half of patients, often involving the facial area and upper extremities - a clinical picture found to misguide less-experienced physicians $[33,35]$. However, the characteristic lesions in hypocomplementemic urticarial vasculitis syndrome are typically painful and often resolve with postinflammatory hyperpigmentation or purpura upon their resolution. These characteristics, including the extracutaneous and systemic involvement, are all uncommon for typical angioedema. The appropriate manage- ment is determined by the severity of the disease, and may include combinations of antihistamines, hydroxychloroquine, corticosteroids and immunosuppression [36].

\section{Clarkson's Disease}

Systemic capillary leak syndrome, also called Clarkson's disease, is a life-threatening condition characterized by recurrent episodes of sudden hypovolemic shock and massive edema due to the capillary leakage of plasma from the intravascular to the extravascular compartments $[37,38]$. The pathogenesis is still unclear, but immune dysregulation may play an essential role. Systemic capillary leak syndrome is diagnosed clinically after exclusion of other diseases caused by systemic capillary leak. A diagnosis of angioedema should be considered upon the initial presentation. Nonetheless, unlike angioedema, the cutaneous swelling of systemic capillary leak syndrome is generalized and symmetrical (fig. 10). Moreover, the rapid shift results also in hypovolemia, hemoconcentration and reduced serum albumin - a triad not characteristic of angioedema. Acute treatment is supportive. Corticoste- 
roids and intravenous immunoglobulin have been reported as beneficial in some cases [37]. No clear strategies for prophylaxis have been defined [38].

\section{Gleich's Syndrome}

The syndrome of episodic angioedema with eosinophilia, also known as Gleich's syndrome, is a rare disorder of unclear etiology characterized by recurrent episodes of idiopathic angioedema, eosinophilia and elevation of the serum immunoglobulin, lasting up to a few months [39]. The clinical picture also demonstrates weight gain caused by fluid retention, fever, pruritus, and, in some cases, urticaria. It is characteristic for the syndrome that there is no systemic organ involvement. The presence of specific laboratory features, together with the other characteristic clinical manifestations, should differentiate this entity from classical angioedema. Although debate surrounds the pathophysiology, increased serum levels of interleukins 5 and 6 has been described $[39,40]$. Systemic corticosteroids are used when treatment is required.

\section{Cluster Headache}

Cluster headache, also known as histamine headache, is a rare cause of unilateral head or facial pain and periorbital edema, often associated with autonomic features such as conjunctival injection, ptosis, pupil constriction, watering of the eyes or rhinitis (fig. 11). Untreated, symptoms last up to a few hours and may recur. Pain is typically intense and resistant to antihistamines and topical steroids. Oral steroids provide relief. Treatment of episodes is usually with rapid-acting tryptan or high-flow oxygen. Verapamil is the drug of choice for prophylaxis [41]. The presence of the characteristic headache, together with the other clinical manifestations, should differentiate this entity from classical angioedema.

\section{Idiopathic Edema}

Idiopathic edema is a self-limited condition of persistent fluid retention, primarily in women [3]. The fluid retention is typically most prominent in premenstrual periods, which is why the condition is also known as 'cyclical edema'. It is most prominent on the extremities or abdomen after a prolonged upright position and also in the facial area, including pronounced periorbital edema, after recumbency overnight (fig. 12). This distinctive alteration over time, combined with an excessive weight gain from morning to evening and pitting edema, is very uncharacteristic for angioedema. Also, the edema is pitting, in contrast to the nonpitting nature of angioedema. The diagnosis is one of exclusion and should only be considered when there is no

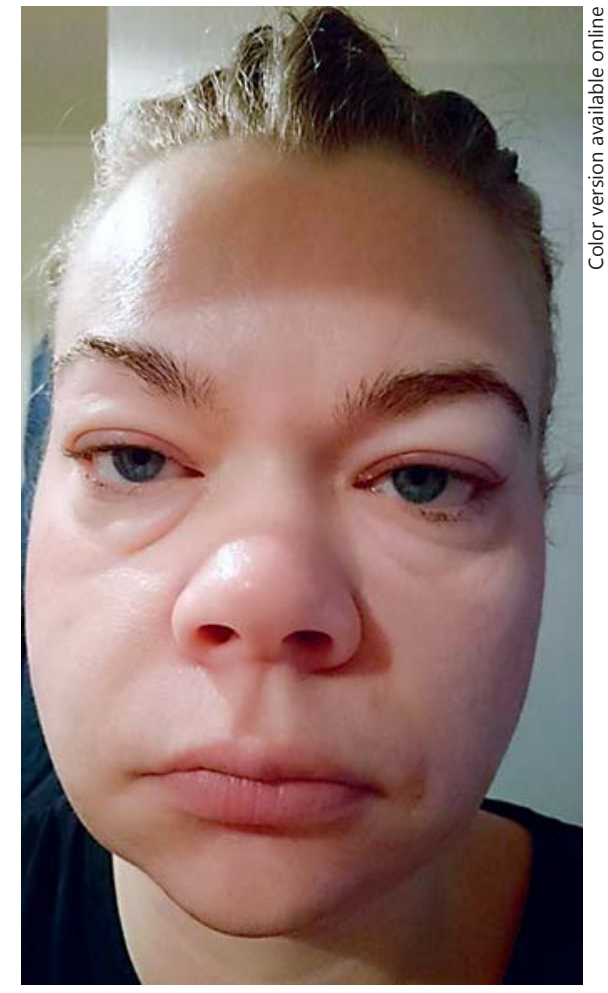

Fig. 12. Fluid retention of the face in a patient with idiopathic edema.

evidence of cardiac, hepatic, renal or thyroid disease, all well-known causes of edema. Patients with idiopathic edema often become dependent on diuretics when trying to minimize the fluid retention. It is therefore important to avoid diuretics and, instead, consider angiotensin-converting enzyme inhibitors when treating these patients [42].

\section{Discussion}

A variety of dermatologic conditions can cause swelling that resembles the diagnosis of angioedema. This review has discussed the most essential diseases that mimic angioedema, the so-called pseudoangioedemas, and also pointing out key features that help clarify the diagnoses and differentiate these from classic angioedema. Working knowledge of this kind is fundamental in the emergency setting when dealing with patients with edema, and the list of diseases should be kept in mind when assessing an atypical angioedema case. In this way, determination of the root cause of symptoms can be made, leading to more effective and appropriate management of sometimes life-threatening conditions. 


\section{Acknowledgements}

\section{References}

1 Quincke HI: Über akutes umschriebenes Hautödem. Monatsh Prakt Dermatol 1882;1: 129-131.

2 Cicardi M, Aberer W, Banerji A, Bas M, Bernstein JA, Bork K, Caballero T, Farkas H, Grumach A, Kaplan AP, Riedl MA, Triggiani M, Zanichelli A, Zuraw B: Classification, diagnosis, and approach to treatment for angioedema: consensus report from the Hereditary Angioedema International Working Group. Allergy 2014;69:602-616.

3 Grigoriadou S, Longhurst HJ: Clinical immunology review series: an approach to the patient with angio-oedema. Clin Exp Immunol 2009;155:367-377.

4 Busse PJ: Angioedema: differential diagnosis and treatment. Allergy Asthma Proc 2011;32: 3-11.

5 Bork K, Barnstedt SE, Koch P, Traupe H: Hereditary angioedema with normal C1-inhibitor activity in women. Lancet 2000;356:213-217.

6 Cichon S, Martin L, Hennies HC, Müller F, Van Driessche K, Karpushova A, Stevens W, Colombo R, Renné T, Drouet C, Bork K, Nöthen MM: Increased activity of coagulation factor XII (Hageman factor) causes hereditary angioedema type III. Am J Hum Genet 2006;79:1098-1104.

7 Björkqvist J, de Maat S, Lewandrowski U, Di Gennaro A, Oschatz C, Schönig K, Nöthen MM, Drouet C, Braley H, Nolte MW, Sickmann A, Panousis C, Mass C, Renné T: Defective glycosylation of coagulation factor XII underlies hereditary angioedema type III. J Clin Invest 2015;125:3132-3146.

8 Dewald G, Bork K: Missense mutations in the coagulation factor XII (Hageman factor) gene in hereditary angioedema with normal $\mathrm{C} 1$ inhibitor. Biochem Biophys Res Commun 2006; 343:1286-1289.

9 Zingale LC, Beltrami L, Zanichelli A, Maggioni L, Pappalardo E, Cicardi B, Cicardi M: Angioedema without urticaria: a large clinical survey. CMAJ 2006;175:1065-1070.

10 Kakimoto C, Sparks C, White AA: Melkersson-Rosenthal syndrome: a form of pseudoangioedema. Ann Allergy Asthma Immunol 2007;99:185-189.

11 Kaplan AP, Greaves MW: Angioedema. J Am Acad Dermatol 2005;53:373-388.

12 Frigas E, Nzeako UC: Angioedema. Clin Rev Allergy Immunol 2002;23:217-231.

13 Tai S, Mascaro M, Goldstein NA: Angioedema: a review of 367 episodes presenting to three tertiary care hospitals. Ann Otol Rhinol Laryngol 2010;119:836-841.

14 Tan CH, Rasool S, Johnston GA: Contact dermatitis: allergic and irritant. Clin Dermatol 2014;32:116-124.

We thank Tarec Christoffer El-Galaly, MD, and Nina Keldsen, MD, for allowing the use of figure 5 (reprinted with permission) [Ugeskr Læger 2007;169:3118] and Knud Bonnet Yderstræde, MD, for allowing the use of figure 10. We also thank Horton Hovedpineforening (Danish Association for Patients with Cluster Headache), www.hortonforeningen.dk for allowing the use of figure 11 .

15 Tukenmez Demirci G, Kivanc Altunay I, Atis G, Kucukunal A: Allergic contact dermatitis mimicking angioedema due to paraphenylendiamine hypersensitivity: a case report. $\mathrm{Cu}-$ $\tan$ Ocul Toxicol 2012;31:250-252.

16 Omairi N El, Abourazzak S, Chaouki S, Atmani S, Hida M: Drug reaction with eosinophilia and systemic symptom (DRESS) induced by carbamazepine: a case report and literature review. Pan Afr Med J 2014;18:1-4.

17 Rasmussen EHR, Bindslev-Jensen C, Bygum A: Angioedema - assessment and treatment. Tidsskr Nor Laegeforen 2012;21:2391-2395.

18 Cacoub P, Musette P, Descamps V, Meyer O, Speirs C, Finzi L, Roujeau JC: The DRESS syndrome: a literature review. Am J Med 2011; 124:588-597.

19 Muro Y, Sugiura K, Akiyama M: Cutaneous manifestations in dermatomyositis: key clini$\mathrm{cal}$ and serological features - a comprehensive review. Clin Rev Allergy Immunol 2015, Epub ahead of print.

20 Milisenda JC, Doti PI, Prieto-Gonzolez S, Grau JM: Dermatomyositis presenting with severe subcutaneous edema: five additional cases and review of the literature. Semin $\mathrm{Ar}$ thritis Rheum 2014;44:228-233.

21 Iaccarino L, Ghirardello A, Bettio S, Zen M, Gatto M, Punzi L, Gatto M: The clinical features, diagnosis and classification of dermatomyositis. J Autoimmun 2014;48-49:122-127.

22 Lamparter J, Kottler U, Cursiefen C, Pfeiffer N, Pitz S: Morbus Morbihan: seltene Ursache ödemaöser Lidschwellungen. Ophthalmologe 2010;107:553-557.

23 Veraldi S, Persico MC, Francia C: Morbihan syndrome. Indian Dermatol Online J 2013;4: 122-124.

24 Fujimoto N, Mitsuru M, Tanaka T: Successful treatment of Morbihan disease with longterm minocycline and its association with mast cell infiltration. Acta Derm Venereol 2015;95:368-369.

25 Burgdorff T, Douwes KE, Bogenrieder T, Szeimies RM, Hohenleutner U, Landthaler M, Stolz W: Superior vena cava syndrome: an important differential diagnosis in patients with facial edema. Acta Derm Venereol 2001; 81:205-206.

26 Wan JF, Bezjak A: Superior vena cava syndrome. Emerg Med Clin North Am 2009;27: 243-255.

27 Van Dellen RG, Maddox DE, Dutta EJ: Masqueraders of angioedema and urticaria. Ann Allergy Asthma Immunol 2002;88:10-15.

28 Roberts CGP, Ladenson PW: Hypothyroidism. Lancet 2004;363:793-803.
29 Cakmak SK, Gönül M, Gül Ü, Kiliç A, Demirel Ö: Subcutaneous emphysema mimicking angioedema. J Dermatol 2006;33:902-903.

30 Maunder R, Pierson D, Hudson L: Subcutaneous and medistinal emphysema. Pathophysiology, diagnosis, and management. Arch Intern Med 1984;144:1447-1453.

31 Celebi Z, Ozguclu S, Aydin O, Okcu A, Soyyigit S: A rare syndrome in the differential diagnosis for angioedema. J Med Cases 2014;5: 579-582.

32 Leâo JC, Hodgson T, Scully C, Porter S: Review article: orofacial granulomatosis. Aliment Pharmacol Ther 2004;20:1019-1027.

33 Wisnieski JJ, Baer AN, Christensen J, Cupps TR, Flagg DN: Hypocomplementemic urticarial vasculitis syndrome. Clinical and serologic findings in 18 patients. Medicine (Baltimore) 1995;74:24-41.

34 Buck A, Christensen J, McCarty M: Hypocomplementemic urticarial vasculitis syndrome: a case report and literature review. J Clin Aesthet Dermatol 2012;5:36-46.

35 Jones JM, Reich KA, Raval DG: Angioedema in a 47-year-old woman with hypocomplementemic urticarial vasculitis syndrome. J Am Osteopat Assoc 2012;112:90-92.

36 Jara LJ, Navarro C, Medina G, Vera-Lastra O, Saavedra MA: Hypocomplementemic urticarial vasculitis syndrome. Curr Rheumatol Rep 2009;11:410-415.

37 Druey KM, Greipp PR: Narrative review: Clarkson disease - systemic capillary leak syndrome. Ann Intern Med 2010;153:90-98.

38 Kapoor P, Greipp PT, Schaefer EW, Mandrekar SJ, Kamal AH, Gonzalez-Paz NC, Kumar S, Greipp PR: Idiopathic systemic capillary leak syndrome (Clarkson's disease): the Mayo Clinic experience. Mayo Clin Proc 2010;85:905-912.

39 Khoury P, Herold J, Alpaugh A, Dinerman E, Holland-Thomas N, Stoddard J, Gurprasad S, Maric I, Simakova O, Schwarts LB, Fong L, Lee CC, Xi L, Wang Z, Raffeld M, Klion AD: Episodic angioedema with eosinophilia (Gleich syndrome) is a multilineage cell cycling disorder. Haematologica 2014;100:300307.

40 Banerji A, Weller PF, Sheikh J: Cytokine-associated angioedema syndromes including episodic angioedema with eosinophilia (Gleich's syndrome). Immunol Allergy Clin North Am 2006;26:769-781.

41 Nesbitt AD, Goadsby PJ: Cluster headache. BMJ 2012;344:e2407.

42 Streeten D: Idiopathic edema. Pathogenesis, clinical features, and treatment. Endocr Metab Clin North Am 1995;24:531-547. 